\title{
Longitudinal analysis of quality of life in patients with undifferentiated connective tissue diseases
}

This article was published in the following Dove Press journal:

Patient Related Outcome Measures

2 February 2017

Number of times this article has been viewed

\section{Michele ludici \\ Rosaria Irace \\ Antonella Riccardi \\ Giovanna Cuomo \\ Serena Vettori \\ Gabriele Valentini}

Rheumatology Section, Department of Clinical and Experimental Medicine, Second University of Naples, Naples, Italy
Correspondence: Michele ludici Rheumatology Section, Department of Clinical and Experimental Medicine, Second University of Naples, Building 3, Via Pansini 5, 80I3I Naples, Italy Tel/fax +39 8I 5666746 Email michele_iudici@hotmail.com
Introduction/objectives: To prospectively assess the quality of life (QoL) of patients affected by undifferentiated connective tissue diseases (UCTDs) and to identify factors associated with changes over time.

Patients and methods: A total of 46 consecutive UCTD patients completed the Short-Form 36 (SF-36) questionnaire at presentation and then yearly. At each 6-month visit, all patients underwent a detailed history taking and a laboratory and physical assessment, in order to follow the evolution of the disease over time and to assess the the co-existence of fibromyalgia. Results: At presentation, scores lower than the average of the general population were detected in $34(74 \%)$ and 41 (89\%) patients in the physical and mental domains, respectively. No difference between patients with and without Raynaud's phenomenon was detected. Fibromyalgia was the only independent variable associated with an impaired physical component summary score $(p=0.0009)$. No patient feature was found to be associated with the basal mental component summary score. During 24 months of follow-up, a significant improvement (ie, a change $\geq 5$ from baseline) in physical component summary and mental component summary scores was observed in $14(33.3 \%)$ and $20(43.4 \%)$ patients, respectively. Patients who significantly improved in the physical domain more frequently had a history of glucocorticoids intake $(p<0.001)$, while those who improved in the mental component more frequently had a history of either glucocorticoids ( $p=0.043$ ) or immunosuppressors $(p=0.037)$ intake during follow-up.

Conclusion: UCTD patients perceive a worse QoL, regardless of Raynaud's phenomenon Fibromyalgia is one of the major contributors of physical QoL, whereas no factor influencing mental component has been identified. An improvement in QoL can be observed in less than half of patients over a 2-year follow-up. Larger studies are needed to identify factors influencing QoL and to define the role of pharmacological treatments.

Keywords: undifferentiated connective tissue diseases, quality of life, glucocorticoids, fibromyalgia

\section{Introduction}

The term undifferentiated connective tissue diseases (UCTDs) encompasses a variety of rare conditions that share clinical and serological features with definite connective tissue diseases (CTDs), but do not fulfill the classification criteria for any of them. ${ }^{1,2}$

Despite a number of studies investigating clinical presentation, ${ }^{3,4}$ disease course, ${ }^{3,5-7}$ prevalence and features of major organ involvement ${ }^{2,3}$ having been published in the past few years, the assessment of health-related quality of life (QoL) has been poorly addressed in UCTD patients. ${ }^{8}$ A few years ago, we conducted a cross-sectional study on patients with UCTD, all of whom presented with Raynaud's 
phenomenon (RP) and pointed out a poor QoL in both physical and mental dimensions. However, we failed to find any association with clinical and serological disease features. ${ }^{9}$ Moreover, no longitudinal data on course of QoL are available for these patients.

We planned this study to assess UCTD patient's QoL changes over time and to identify demographic, clinical, serological and therapeutic factors associated with them.

\section{Patients and methods}

\section{Inclusion/exclusion criteria}

UCTD patients consecutively admitted to the outpatient clinic of the Rheumatology Unit of the Second University of Naples, who had completed at least 2 Short-Form 36 (SF-36) questionnaires, ${ }^{10,11}$ with a minimum difference between them of 1 year, were enrolled in the study, after providing written informed consent.

According to Doria et al, ${ }^{1}$ to be diagnosed with UCTD, the patients had to present: 1) signs and symptoms suggestive of a CTD without fulfilling the criteria of any defined $\mathrm{CTD}^{12-16}$; 2) positivity for anti-nuclear antibodies (ANA) in the absence of other known conditions associated with ANA positivity (ie, chronic $\mathrm{B}$ or $\mathrm{C}$ hepatitis infection, autoimmune thyroid and hepatic disorders, malignancies) and 3) disease duration as assessed from the onset of the first symptom/sign $\geq 3$ years.

Patients were excluded if during follow-up they developed any clinical manifestation (ie, malar rash, subacute cutaneous lupus erythematosus, chronic cutaneous lupus erythematosus, skin sclerosis, heliotrope rash, Gottron's plaque, erosive arthritis) or any autoantibody (anti-dsDNA, anti-Sm, antiribosomal $\mathrm{P}$ protein, anti-Scl 70, ACA, anti-SSB, anti-Jo1, anti-Mi-2) typical of a definite CTD. ${ }^{1}$

\section{Assessment of QoL}

Each patient was asked to complete the Italian version of the self-administered questionnaires SF-36, ${ }^{10}$ which consists of 36 questions grouped into 8 domains: physical functioning (PF), social functioning (SF), role limitations related to physical problems (RoP), role limitations related to emotional problems (RE), mental health $(\mathrm{MH})$, vitality (VT), bodily pain (BP) and general health $(\mathrm{GH})$ perception. A score ranging from 0 (indicating the worse health status) to 100 (indicating the best health status) is assigned for each domain. Domain scores can be summarized into a physical component summary (PCS) score and a mental component summary (MCS) score. ${ }^{10}$ For these 2 summary scales, a score $<50$ reflects a worse HRQOL compared to the average score of the general population. ${ }^{10}$ Data from questionnaires completed at study entry and at the last visit were considered. At the last visit, an increase of $\geq 5$ from baseline in either PCS or MCS score was defined as a clinically significant improvement. ${ }^{17}$ According to data from studies in patients affected by other rheumatological conditions, ${ }^{18-20}$ a change of $\geq 10$ from baseline was considered significant for each of the 8 SF-36 domains. In addition, information about educational and occupational status for each patient was collected.

\section{Clinical assessment of patients}

According to standard clinical practice and to ensure a correct classification, at study entry and then at each 6-month visit, all patients underwent a detailed history taking and a physical examination to identify the above-listed inclusion and exclusion features. Moreover, because of the known impact that fibromyalgia has on QoL, each patient was investigated to assess the co-existence of fibromyalgia. We chose to use the 1990 American College of Rheumatology classification criteria because they had been largely validated in cohort studies at the start of the study. ${ }^{21}$ In addition, in order to investigate the course of QoL over time, the changes in mental and physical domains were assessed and features associated with them were searched. Finally, at each visit, we investigated the presence of clinical manifestations (Table 1) subdivided into 8 domains (systemic features, musculoskeletal, mucocutaneous, peripheral vascular, cardiopulmonary,

Table I Clinical manifestations routinely assessed in UCTD patients

\begin{tabular}{ll}
\hline Domain & Manifestations \\
\hline Systemic & Fever \\
& Asthenia \\
Musculoskeletal & Arthrt loss \\
& Myalgias/muscle weakness \\
Mucocutaneous & Photosensitivity \\
& Hair loss \\
& Teleangectasias \\
& Livedo reticularis \\
& Purpura \\
& Oral/nasal ulcers \\
Peripheral vascular & Other skin lesions* \\
Cardiopulmonary & Raynaud's phenomenon, acrocyanosis \\
& Shortness of breath \\
Gastrointestinal & Serositis \\
& Dysphagia/heartburn \\
Lacrimal and salivar glands & Early satiety \\
function & Eye dryness (Schirmer's test $)^{34}$ \\
Peripheral neuropathy & Oral dryness (scialometry) \\
\hline Not & Carpal tunnel syndrome \\
\hline
\end{tabular}

Note: *Macular rash and panniculitis.

Abbreviation: UCTD, undifferentiated connective tissue disease. 
gastrointestinal, lacrimal and salivar glands function and peripheral neuropathy).

\section{Laboratory assessment of patients}

ANA and CTD marker autoantibodies (ie, anti-DNA-topoisomerase I - anti-Scl-70, ACA, anti-RNA polymerase III, anti-PM/Scl, anti-Th/To, anti-SSA, anti-SSB, anti-Sm, antiJo1, anti-P protein, anti-Mi-2, anti-RNP and anti-DNAds antibodies) were investigated as already reported ${ }^{22}$ on sera stored at $-20^{\circ} \mathrm{C}$ and heated at $56^{\circ} \mathrm{C}$ for $30 \mathrm{~min}$ before testing. ANA were considered positive when detected by indirect immunofluorescence on HEp-2 cells at a dilution of $\geq 1: 160$. At study entry and then yearly, a venous blood sample was obtained to perform the following laboratory investigations: cell blood count, urinalysis, creatinine, alanine aminotransferase (ALT), aspartate aminotransferase (AST), creatine kinase, erythrocyte sedimentation rate (ESR), C-reactive protein (CRP), serum protein electrophoresis and serum $\mathrm{C} 3$ and $\mathrm{C} 4$ concentrations and ANA and CTD marker autoantibodies. Changes in ESR, CRP, C3, C4 and hemoglobin were compared with those observed in PCS and MCS.

\section{Treatment}

At first observation, UCTD patients were treated according to standard therapy depending on the clinical picture: hydroxychloroquine (up to $6.5 \mathrm{mg} / \mathrm{kg} /$ daily) for mucocutaneous and articular involvement; low-dose steroids $(\leq 7.5 \mathrm{mg}$ of prednisone equivalent daily) for systemic features or mucocutaneous, articular, cardiopulmonary (serositis) manifestations unresponsive to hydroxychloroquine; methotrexate (up to $25 \mathrm{mg} /$ week) for synovitis unresponsive to a combination of hydroxychloroquine and low-dose steroids; azathioprine ( $2 \mathrm{mg} / \mathrm{kg} /$ daily) in case of persistency of cardiopulmonary manifestations and increased inflammation markers despite the treatment with a combination of hydroxychloroquine and low-dose steroids, and lacrimal and salivary substitutes in case of ocular or oral dryness.

This study was approved by the ethical committee of Azienda Ospedaliera Universitaria, Seconda Università di Napoli. All patients agreed to participate in the study and provided written informed consent.

\section{Statistical analysis}

Descriptive statistics were used to summarize the patients' baseline characteristics. The chi-squared test was used for comparison of proportions. Mann-Whitney or Wilcoxon nonparametric tests were used for between-group comparisons, where appropriate. Linear regression analysis was carried out to find factors associated with health-related QoL parameters or with their changes over time. A $p$ value $<0.05$ was considered statistically significant. MedCalc software, version 12.7.0.0, was used to perform statistical analysis.

\section{Results \\ Demographic and clinical features at study entry}

From January 1, 2011, to December 31, 2013, 55 consecutive Caucasian UCTD patients were enrolled in the study after giving a written informed consent. Among them, 2 were excluded because of missing response at baseline SF-36 and 1 because of refusing to complete the questionnaire at the follow-up visit. One patient was lost to follow-up. A total of 5 patients had a diagnosis of definite CTD during the followup (2 systemic sclerosis, 2 systemic lupus and 1 Sjogren's syndrome) and were then excluded from the study.

Overall, 46 patients were included in the study. They were mostly female (95.6\%), with a mean (standard deviation [SD]) age of $44.5 \pm 12.8$ years and a mean (SD) disease duration of $7.5 \pm 5.5$ years. The majority of patients $(65 \%)$ received a secondary education, $30(65 \%)$ were employed and $3(6.5 \%)$ were retired. At study entry, the most frequent clinical manifestations were arthralgia/arthritis (45.6\%), Raynaud's phenomenon (45.6\%), ocular and/or oral dryness (32.6\%), esophagogastric symptoms (32.6\%), myalgia (26.0\%) and asthenia (26.0\%). A total of 16 patients (35\%) also had fibromyalgia. At baseline, hydroxychloroquine was prescribed to 28 patients ( 24 with articular involvement and 4 with skin lesions), low-dose glucocorticoids (GCs) to 16 patients ( 12 with systemic features and 4 with persistent skin and/or articular inflammation despite antimalarials), azathioprine to 7 patients with cardiopulmonary manifestations and methotrexate to 3 patients with synovitis unresponsive to combination of GCs and hydroxychloroquine. Table 2 lists the main demographic, clinical and laboratory features of the patients enrolled.

\section{SF-36 scores and factors associated with QoL at study entry}

At study entry, most of the patient scores were lower than the average of general population in either physical or mental domains. Actually, a PCS score and an MCS score $>50$ were detected in only $12(26 \%)$ and $5(11 \%)$ patients . The lowest scores were recorded in RE (median 33; range 0-100), VT (median 45; range 5-90) and GH perception (median 46; range 5-92). 
Table 2 Main baseline demographic and clinical features of the 46 UCTD patients enrolled

\begin{tabular}{ll}
\hline Patients' features & \\
Female, $\mathrm{n}(\%)$ & $44(95.6)$ \\
Age (years), mean \pm SD & $44.5 \pm 12.8$ \\
Disease duration (years), mean \pm SD & $7.5 \pm 5.5$ \\
Clinical features & \\
Systemic, $\mathrm{n}(\%)$ & $12(26.0)$ \\
Mucocutaneous, $\mathrm{n}(\%)$ & $5(10.8)$ \\
Peripheral vascular, $\mathrm{n}(\%)$ & $23(50.0)$ \\
Musculoskeletal, $\mathrm{n}(\%)$ & $33(71.7)$ \\
Gastrointestinal, $\mathrm{n}(\%)$ & $15(32.6)$ \\
Cardiopulmonary, $\mathrm{n}(\%)$ & $9(19.5)$ \\
Oral and/or ocular dryness, $\mathrm{n}(\%)$ & $15(32.6)$ \\
Peripheral nervous system, $\mathrm{n}(\%)$ & $6(13.0)$ \\
Laboratory features & \\
Anti-nuclear positivity, $\mathrm{n}(\%)$ & $46(100)$ \\
Anti-SSA positive, $\mathrm{n}(\%)$ & $7(15.2)$ \\
Anti-RNP positive, $\mathrm{n}(\%)$ & $3(6.5)$ \\
ESR $\geq 30$ mm/Hg, $\mathrm{n}(\%)$ & $6(13.0)$ \\
CRP $\geq \mathrm{I}$ mg/dL, $\mathrm{n}(\%)$ & $3(6.5)$ \\
Hypocomplementemia, $\mathrm{n}(\%)$ & $7(15.2)$ \\
Anemia, $\mathrm{n}(\%)$ & $6(13.0)$ \\
Leukopenia, $\mathrm{n}$ (\%) & $\mathrm{I}(2.1)$ \\
Lymphopenia, $\mathrm{n}(\%)$ & $3(6.5)$ \\
Thrombocytopenia, $\mathrm{n}(\%)$ & 0 \\
\hline Ab &
\end{tabular}

Abbreviations: UCTD, undifferentiated connective tissue disease; SD, standard deviation; ESR, erythrocyte sedimentation rate; CRP, C-reactive protein.

At baseline, PCS resulted to be significantly lower in patients with asthenia (median 34, range 5-60 vs median 44 , range $16-65 ; p=0.037$ ) and with a diagnosis of fibromyalgia (median 32, range 5-52 vs median 45, range 21-65; $p=0.0005)$. In a linear regression model, fibromyalgia resulted to be the only independent variable associated with an impaired PCS and explained its $28 \%$ variance $\left(R^{2}=0.284\right.$; $p=0.0009$ ). No other demographic, clinical and serologic features of patients were found to be associated with PCS. No feature of patients was found to be associated with basal MCS scores. Interestingly, no difference in both MCS and PCS scores were found between patients with or without Raynaud's phenomenon. Table 3 lists the results of the 8 SF-36 domains and of each of the 2 summary scores at the first observation.

\section{Follow-up data}

Compared to baseline, a significant improvement occurred in PF in 18 (39.1\%) patients, RoP in 10 (21.7\%) patients, $\mathrm{BP}$ in $11(23.9 \%)$ patients, GH in $12(26.0 \%)$ patients, VT in $15(32.6 \%)$ patients, SF in $14(30.4 \%)$, RE in $11(23.9 \%)$ patients and $\mathrm{MH}$ in $10(21.7 \%)$ patients (Table 3 ).

As far as the summary scores, a significant improvement in PCS or MCS score was observed in 14 (33.3\%) and $20(43.4 \%)$ patients, respectively.
The following treatments were prescribed during the study period: hydroxychloroquine for 34 patients $(73.9 \%)$, low to medium dose of GCs for 18 (39.1\%) patients and immunosuppressants for $11(23.9 \%)$ patients, namely, azathioprine for 7 patients and methotrexate for 4 patients (for arthritis in 3 patients unresponsive or with contraindications to antimalarials and for myositis in 1 patient). The GCs had been prescribed in a median dose of $2.5 \mathrm{mg}$ (range 2.5-7.5 mg).

During 24 months (range 12-36 months) follow-up period, a median of 1 (range $0-8$ ) clinical manifestation not present at study entry was recorded in each patient. The new clinical manifestations developed were systemic (fatigue) in 14 patients, muscular in 13 patients, cutaneous in 11 patients, gastrointestinal in 10 patients, articular in 7 patients, peripheral vascular in 6 patients, oral and/or ocular dryness in 4 patients, acral paresthesias in 4 patients and respiratory in 2 patients. At the last visit, a median of 3 (range $0-8$ ) clinical manifestations were still present in the patients investigated.

No associations were detected between either $\triangle \mathrm{PCS}$ or $\Delta \mathrm{MCS}$ and $\Delta \mathrm{ESR}$ ( $p=0.878$ and $p=0.562$, respectively), $\Delta \mathrm{CRP}(p=0.543$ and $p=776$, respectively), $\Delta \mathrm{C} 3(p=0.509$ and $p=0.454$, respectively), $\Delta \mathrm{C} 4$ ( $p=0.301$ and $p=0.561$, respectively) and $\Delta$ hemoglobin ( $p=0.234$ and $p=0.945$, respectively). Although one-third of patients had significantly improved, a PCS or an MCS score above that of the average score of the general population was recorded in only $12(26.0 \%)$ and $6(13.0 \%)$ patients, respectively. Moreover, patients who significantly improved in the physical domain had more frequently a history of GCs intake (14/14 vs $20 / 32 ; p=0.0008$ ) than those who did not improve, and those patients whose mental component of QoL significantly improved had more frequently a history of either GCs $(18 / 20$ vs $16 / 26 ; p=0.043)$ or immunosuppressive drugs $(8 / 20$ vs $3 / 26 ; p=0.037)$ intake during follow-up.

\section{Impact of fibromyalgia on QoL in UCTD patients}

Because of the known impact of fibromyalgia on QoL of patients affected by autoimmune diseases, ${ }^{23}$ we investigated if the presence of this comorbidity affected QoL parameters in our cohort. Fibromyalgia was found to be the only factor independently associated with PCS both at study entry $\left(R^{2}=0.284 ; p=0.0009\right)$ and at the last visit $\left(R^{2}=0.289\right.$, $p=0.0001)$. No significant association was instead observed with $\operatorname{MCS}(p=0.234$ at baseline and $p=0.146$ at the last visit). Nevertheless, we did not detect any association between fibromyalgia and either $\Delta \mathrm{PCS}(p=0.440)$ or $\Delta \mathrm{MCS}$ 
Table 3 SF-36 scores at study entry and their changes over time

\begin{tabular}{|c|c|c|c|c|}
\hline SF-36 domains & $\begin{array}{l}\text { Baseline } \\
\text { score, median } \\
\text { (range) }\end{array}$ & $\begin{array}{l}\text { Patients with marginal } \\
\text { changes }(\geq 5-<10) \\
\text { during FU, } n(\%)\end{array}$ & $\begin{array}{l}\text { Patients with clear } \\
\text { improvement }(\geq 10) \\
\text { during FU, n (\%) }\end{array}$ & $\begin{array}{l}\text { Patients with score }>50 \text { at } \\
\text { the end of the FU, n (\%) }\end{array}$ \\
\hline PF, median (range) & $75(5-100)$ & $5(10.8)$ & $18(39.1)$ & $31(67.3)$ \\
\hline RoP, median (range) & $50(0-100)$ & 0 & $10(21.7)$ & $19(41.3)$ \\
\hline BP, median (range) & $51(12-100)$ & $7(I 5.2)$ & II (23.9) & $21(45.6)$ \\
\hline GH, median (range) & $46(5-92)$ & $4(8.6)$ & $12(26.0)$ & $13(28.2)$ \\
\hline VT, median (range) & $45(5-90)$ & $5(10.8)$ & $15(32.6)$ & $14(30.4)$ \\
\hline SF, median (range) & $62(12-100)$ & 0 & $14(30.4)$ & $22(47.8)$ \\
\hline RE, median (range) & $33(0-100)$ & 0 & II (23.9) & $24(52.1)$ \\
\hline $\mathrm{MH}$, median (range) & $52(20-100)$ & $6(13.0)$ & $10(21.7)$ & $29(63.0)$ \\
\hline PCS score, median (range) & $4 I(5-65)$ & NA & $14(33.3)^{*}$ & $12(26.0)$ \\
\hline MCS score, median (range) & $39.5(23-60)$ & NA & $20(43.4)^{*}$ & $6(13.0)$ \\
\hline
\end{tabular}

Note: *Significant improvement is defined as an increase $\geq 5$ points from baseline.

Abbreviations: SF-36, Short-Form 36; FU, follow-up; PF, physical functioning; RoP, role limitations related to physical problems; BP, bodily pain; GH, general health; VT, vitality; SF, social functioning; RE, role limitations related to emotional problems; $\mathrm{MH}$, mental health; PCS, physical component summary; MCS, mental component summary; NA, not applicable.

( $p=0.711$ ) over time. Actually, the number of patients with fibromyalgia experiencing a significant improvement in either PCS or MCS was not significantly different from those without fibromyalgia, $(5 / 14$ vs $11 / 32 ; p=0.999)$ and (6/20 vs 10/26), respectively. Finally, as expected, we did not find any significant impact of GCs or immunosuppressants on the control of fibromyalgia-related symptoms (data not shown).

\section{Discussion}

To the best of our knowledge, this is the first study devoted to investigate QoL in UCTD patients with or without RP and its evolution over time.

A few years ago, we investigated QoL, as assessed by the SF-36 questionnaire, in 35 patients with UCTD, all of whom presented with RP. ${ }^{9}$ In most of them, QoL scores resulted to be lower than those of a control group from the general population.

In the present study, we compared QoL of patients with and without RP and failed to find any significant difference. Actually, in both subsets, a worse physical- and mentalrelated QoL than general population was observed. These results confirm that knowing to have a chronic disease, even if mild and slowly evolutive, has a significant impact on QoL. ${ }^{24}$ In particular, in our UCTD patients, we pointed out a high prevalence of fatigue, as assessed by VT domain of SF-36, which is a frequent and disabling symptom reported by patients with chronic diseases, as well as an impairment of RE dimension, which reflects the presence of diseaserelated emotional problems and may impact work or other daily activities.

Fibromyalgia is a condition often associated with chronic autoimmune diseases. ${ }^{23}$ Its presence has been found to heavily influence the QoL of patients with $\mathrm{CTD},{ }^{25}$ and it has been reported to be one of the main contributors of health status and it changes over time in systemic lupus erythematosus (SLE) patients. ${ }^{26}$ Our results are in line with most of these findings. In fact, we confirmed that fibromyalgia is independently associated with a worse QoL related to physical problems. However, one difference to be highlighted is that we did not observe any association with the MCS score both at baseline and at the last observation.

We also assessed changes in QoL over time and investigated factors associated with any change. We found that both mental and physical domains of QoL improved in $\sim 40 \%$ and $\sim 30 \%$ of patients, respectively. These findings are in line with the figure observed by Urowitz et $\mathrm{al}^{27}$ in a larger cohort of SLE patients in whom a minimum clinically important improvement was achieved by approximately half of them.

A history of GCs and immunosuppressive intake was observed more frequently in patients whose QoL improved. Immunosuppressors and GCs are drugs quite commonly used in UCTD patients. ${ }^{28}$ One might argue that the efficacy of these drugs to control most of the disease manifestations might explain the achievement of a better QoL. However, the absence of validated criteria to define response to treatment does not allow to support this conclusion. However, it might be hypothesized that taking drugs known as effective improves the sense of well-being independent of the effects on disease manifestations. In this regard, it is known that the relationship between drug efficacy and QoL improvement is not the rule in CTD patients. Actually, Urowitz et $\mathrm{al}^{27}$ reported that changes in SF-36 occurring over time in SLE patients were not affected by steroid use but only by the presence of fibromyalgia. In the EXPLORER trial, no differences 
in QoL parameters as assessed by LupusQoL occurred in rituximab-treated patients compared to the placebo group. ${ }^{29}$ Nevertheless, Strand et $\mathrm{al}^{30}$ reported a significant difference in QoL assessed by SF-36 between drug-treated and placebotreated patients in a trial investigating the efficacy of LJP 394 in 179 SLE patients, and the same finding was recently demonstrated in a belimumab trial. ${ }^{31}$

This study has some limitations. First, it was performed on a small sample of patients recruited in a tertiary referral center. Moreover, we did not investigate psychosocial (ie, social support) and behavioral variables (ie, helplessness, coping with illness) that might have influenced the QoL of patients. ${ }^{32,33}$ Finally, the lack of validated treatment response criteria has hampered to better estimate the overall impact of treatments on disease itself and their relationships with QoL. A consensus aiming to identify such criteria should be planned in the near future.

\section{Conclusion}

We have pointed out that UCTD patients perceive a worse physical and mental QoL compared to general population and that it remains stable in the majority of patients over a 2-year follow-up period. If present, a significant improvement occurs more frequently in patients who had been treated with immunosuppressants or GCs. Such an improvement leads to the achievement of significant better scores in mental QoL, whereas changes in physical domains are milder. Among the factors investigated, fibromyalgia has been found to be the main contributor of an impaired physical QoL.

\section{Disclosure}

The authors report no conflicts of interest in this work.

\section{References}

1. Doria A, Mosca M, Gambari PF, Bombardieri S. Defining unclassifiable connective tissue diseases: incomplete, undifferentiated, or both? J Rheumatol. 2005;32(2):213-215.

2. Mosca M, Tani C, Vagnani S, Carli L, Bombardieri S. The diagnosis and classification of undifferentiated connective tissue diseases. J Autoimmun. 2014;48-49:50-52.

3. Mosca M, Tani C, Carli L, et al. Analysis of the evolution of UCTD to defined CTD after a long term follow-up. Clin Exp Rheumatol. 2013;31(3):471.

4. Cavazzana I, Franceschini F, Belfiore N, et al. Undifferentiated connective tissue disease with antibodies to Ro/SSA: clinical features and follow up of 148 patients. Clin Exp Rheumatol. 2011;19(4):403-409.

5. Bodolay E, Csiki Z, Szekanecz Z, et al. Five-year follow-up of 665 Hungarian patients with undifferentiated connective tissue disease (UCTD). Clin Exp Rheumatol. 2003;21(3):313-320.

6. Calvo-Alén J, Alarcón GS, Burgard SL, Burst N, Bartolucci AA, Williams HJ. Systemic lupus erythematosus: predictors of its occurrence among a cohort of patients with early undifferentiated connective tissue disease: multivariate analyses and identification of risk factors. J Rheumatol. 1996;23(3):469-475.
7. Williams HJ, Alarcón GS, Joks R, et al. Early undifferentiated tissue disease. VI. An inception cohort after 10 years: disease remissions and changes in diagnoses in well established and undifferentiated CTD. J Rheumatol. 1999;26(4):816-825.

8. Mosca M, Tani C, Carli L, Bombardieri S. Undifferentiated CTD: a wide spectrum of autoimmune diseases. Best Pract Res Clin Rheumatol. 2012;26(1):73-77.

9. Iudici M, Cuomo G, Vettori S, Avellino M, Valentini G. Quality of life as measured by the short-form 36 (SF-36) questionnaire in patients with early systemic sclerosis and undifferentiated connective tissue disease. Health Qual Life Outcomes. 2013;11:23.

10. Apolone G, Mosconi P. The Italian SF-36 Health Survey: translation, validation and norming. J Clin Epidemiol. 1998;51(11): 1025-1036.

11. Ware JE Jr, Gandek B, Kosinski M, et al. The equivalence of SF-36 summary health scores estimated using standard and country-specific algorithms in 10 countries: results from the IQOLA Project. International Quality of Life Assessment. J Clin Epidemiol. 1998;51(11): $1167-1170$.

12. Tan EM, Cohen AS, Fries JF, et al. The 1982 revised criteria for the classification of systemic lupus erythematosus. Arthritis Rheum. 1982;25:1271-1277.

13. Subcommittee for Scleroderma Criteria of the American Rheumatism Association Diagnostic and Therapeutic Criteria Committee. Preliminary criteria for the classification of systemic sclerosis (scleroderma). Arthritis Rheum. 1980;23(5):581-590.

14. Vitali C, Bombardieri S, Jonsson R, et al. Classification criteria for Sjögren's syndrome: a revised version of the European criteria proposed by the American-European Consensus Group. Ann Rheum Dis. 2002;61(6):554-555.

15. Bohan A, Peter JB, Bowman RL, Pearson CM. Computer-assisted analysis of 153 patients with polymyositis and dermatomyositis. Medicine (Baltimore). 1977;56(4):255-286.

16. Arnett FC, Edworthy SM, Bloch DA, et al. The American Rheumatism Association 1987 revised criteria for the classification of rheumatoid arthritis. Arthritis Rheum. 1988;31(3):315-324.

17. Norman GR, Sloan JA, Wyrwich KW. Interpretation of changes in health-related quality of life: the remarkable universality of half a standard deviation. Med Care. 2003;41(5):582-592.

18. Strand V, Crawford B, Singh J, Choy E, Smolen JS, Khanna D. Use of "spydergrams" to present and interpret SF-36 health-related quality of life data across rheumatic diseases. Ann Rheum Dis. 2009;68(12): 1800-1804.

19. Strand V, Singh JA. Newer biological agents in rheumatoid arthritis: impact on health-related quality of life and productivity. Drugs. 2010;70(2):121-145.

20. Strand V, Crawford B. Improvement in health-related quality of life in patients with SLE following sustained reductions in antidsDNA antibodies. Expert Rev Pharmacoecon Outcomes Res. 2005; 5(3):317-326.

21. Wolfe F, Smythe HA, Yunus MB, et al. The American College of Rheumatology 1990 criteria for the classification of fibromyalgia. Report of the Multicenter Criteria Committee. Arthritis Rheum. 1990;33(2): $160-172$.

22. Valentini G, Cuomo G, Abignano G, et al. Early systemic sclerosis: assessment of clinical and pre-clinical organ involvement in patients with different disease features. Rheumatology (Oxford). 2011;50(2): 317-323.

23. Atzeni F, Cazzola M, Benucci M, Di Franco M, Salaffi F, Sarzi-Puttini P. Chronic widespread pain in the spectrum of rheumatological diseases. Best Pract Res Clin Rheumatol. 2011;25(2):165-171.

24. Boers M, Kirwan JR, Gossec L, et al. How to choose core outcome measurement sets for clinical trials: OMERACT 11 approves filter 2.0. J Rheumatol. 2014;41(5):1025-1030.

25. Gladman DD, Urowitz MB, Gough J, MacKinnon A. Fibromyalgia is a major contributor to quality of life in lupus. J Rheumatol. 1997; 24(11):2145-2148. 
26. Kuriya B, Gladman DD, Ibañez D, Urowitz MB. Quality of life over time in patients with systemic lupus erythematosus. Arthritis Rheum. 2008;59(2):181-185.

27. Urowitz M, Gladman DD, Ibañez D, et al. Changes in quality of life in the first 5 years of disease in a multicenter cohort of patients with systemic lupus erythematosus. Arthritis Care Res (Hoboken). 2014;66(9):1374-1379.

28. Vaz CC, Couto M, Medeiros D, et al. Undifferentiated connective tissue disease: a seven-center cross-sectional study of 184 patients. Clin Rheumatol. 2009;28(8):915-921.

29. Merrill JT, Neuwelt CM, Wallace DJ, et al. Efficacy and safety of rituximab in moderately-to-severely active systemic lupus erythematosus: the randomized, double-blind, phase II/III systemic lupus erythematosus evaluation of rituximab trial. Arthritis Rheum. 2010;62(1):222-233.

30. Strand V, Aranow C, Cardiel MH, et al. LJP 394 Investigator Consortium. Improvement in health-related quality of life in systemic lupus erythematosus patients enrolled in a randomized clinical trial comparing LJP 394 treatment with placebo. Lupus. 2003;12(9):677-686.
31. Strand V, Levy RA, Cervera R, et al. Improvements in health-related quality of life with belimumab, a B-lymphocyte stimulator-specific inhibitor, in patients with autoantibody-positive systemic lupus erythematosus from the randomised controlled BLISS trials. Ann Rheum Dis. 2014;73(5):838-844.

32. Friedman AW, Alarcón GS, McGwin G Jr, et al. Systemic lupus erythematosus in three ethnic groups. IV. Factors associated with self-reported functional outcome in a large cohort study. LUMINA Study Group. Lupus in Minority Populations, Nature versus Nurture. Arthritis Care Res. 1999;12(4):256-266.

33. Sutcliffe N, Clarke AE, Levinton C, Frost C, Gordon C, Isenberg DA. Associates of health status in patients with systemic lupus erythematosus. J Rheumatol. 1999;26(11):2352-2356.

34. Prause JU. Clinical ophthalmological tests for the diagnosis of keratoconjunctivitis sicca. Clin Exp Rheumatol. 1989;7(2):141-144.

35. Löfgren CD, Wickström C, Sonesson M, Lagunas PT, Christersson C. A systematic review of methods to diagnose oral dryness and salivary gland function. BMC Oral Health. 2012;12:29.
Patient Related Outcome Measures

\section{Publish your work in this journal}

Patient Related Outcome Measures is an international, peer-reviewed, open access journal focusing on treatment outcomes specifically relevant to patients. All aspects of patient care are addressed within the journal and practitioners from all disciplines are invited to submit their work as well as healthcare researchers and patient support groups.

\section{Dovepress}

The journal is included in PubMed. The manuscript management system is completely online and includes a very quick and fair peer-review system. Visit http://www.dovepress.com/testimonials.php to read real quotes from published authors.

Submit your manuscript here: http://www.dovepress.com/patient-related-outcome-measures-journal 